International Journal of Applied Linguistics \& English Literature

ISSN 2200-3592 (Print), ISSN 2200-3452 (Online)

Vol. 1 No. 7; November 2012 [Special Issue on Applied Linguistics]

\title{
Metaphoric Expressions and Their Relation to the Coherence and Unity of Literary Texts
}

\author{
Mina Abbasi Bonabi (PhD candidate in TEFL) \\ Payam-e- Noor University, Iran \\ E-mail: mina_abbasi89@yahoo.com \\ Hasan Iravani (PhD in TEFL) \\ Payam-e- Noor University, Iran \\ E-mail: iravani_tefl@yahoo.com
}

Received: 27-09- 2012

Accepted: 27-10- 2012

Published: 25-11- 2012

doi:10.7575/ijalel.v.1n.7p.137

URL: http://dx.doi.org/10.7575/ijalel.v.1n.7p.137

\begin{abstract}
The paper is an attempt to investigate the underlying discoursal functions of metaphors in terms of their contribution to the creation of discoursal coherence in literary text-type. Metaphoric expressions are not ornamental aspects of speech. Rather they are necessary parts of language. In other words, metaphors are not additional linguistic elements which are imposed on ordinary language. Rather metaphors are a necessary part of language and hence they can be considered the core elements of the texts developing and elaborating the topic of the texts. Following this line of thinking, the aim of this paper is to illustrate in which ways the metaphoric expressions used within a text are core elements and how they contribute to the development and elaboration of the topic of the text in literary text-type. We speculate that metaphors within a text, being core elements, are coherently linked to each other on the one hand and to the topic of the text on the other hand. In this paper, we want to find out how the metaphoric expressions used in the literary texts contribute to the establishment of local coherence and enhance the unity of the text in literature text-type. In other words, we are interested to explore how this relatedness increases the unity of the text and establishes the coherence of the whole text in this text-type. It is of special interest to find out in which ways the contribution of metaphoric expressions to the coherence and unity of the text produce literary effect in literature texts. For this purpose a literature text (a poem by Andrew Marvell) has been selected as our data to be analyzed in terms of the use of metaphors within the text and their relations to the coherence and unity of the text. Through the analysis of our data, we found out that in literature text-type, metaphoric expressions are coherently related to each other and these coherent connections among metaphors and their relation to the topic of the text create the literary effect in literature texts. We also investigated the degree of metaphoric force of metaphoric elements in our analyzed text. We found out that in literature text-type the metaphors have strong metaphoric force and this metaphoric force is created not only by new metaphors but also by the strategic uses of some conventional metaphors. We concluded that metaphor being a necessary and core part of a text may contribute to fulfill different functions in different texts. In the case of literary texts, metaphors, in addition to fulfilling other functions, enhance the unity of the text and by doing so produce literary effect of the text. Besides, on the basis of the analysis of our data, we also suggest that appearance of metaphors in specific instances of language use is not a matter of text. Rather metaphors directly evolve from the discourse elaboration process.
\end{abstract}

Keywords: Coherence and unity, conventional metaphors, new metaphors, metaphoric force, strategic use of metaphors

\section{Introduction}

Contrary to the traditional view which regards metaphor as 'an ornamental aspect of speech and thought' (Tendahl and Gibbes, 2008, p: 1823), in many of the recent studies done in the fields of cognitive linguistics, metaphors are found to be necessary part of language and thought (ibid). Following this line of thinking, we suggest that metaphors are not additional linguistic elements which are imposed on ordinary language to add 
International Journal of Applied Linguistics \& English Literature

ISSN 2200-3592 (Print), ISSN 2200-3452 (Online)

Vol. 1 No. 7; November 2012 [Special Issue on Applied Linguistics]

specific meaning to the meaning potential of texts. Rather it is proved that metaphors are necessary parts of language. The aim of this paper is to demonstrate in which ways the metaphoric expressions used within a text are nucleus elements clarifying and enhancing the topic of the text. We speculate that metaphors within a text, being core elements, are coherently linked to each other on the one hand and to the topic of the text on the other hand. We suggest that these coherent connections among the metaphoric elements on the one hand and the topic of the text on the other is a general characteristic of texts belonging to all text-types. However in this paper we restrict ourselves to literature text-type. It can be the concern of a further research to look at the variations in the degree of coherent connections of metaphoric elements within a text and their relatedness to the topic of the text across different genres. The concern of this paper is to illustrate how the coherent connections among metaphoric expressions within a literary text enhance the unity of the text and reinforce its intentional meaning. The approach adopted here to study metaphor is the 'discourse dynamics approach' (Gibbs, R. and Cameron, L., 2008, p: 74). This approach rather than focusing on systematic relations between isolated metaphorical statements, tries to explain the emergence of certain metaphorical ways of talking-and-thinking (ibid). That is to say, the discourse dynamics approach tries to adopt a functional approach to the study of metaphor, taking into consideration the use of metaphors in the real instances of use.

\section{Different Metaphor Theories}

Traditional theory of metaphor which is strongly rejected by Lakoff and Johnson (1999) has some basic tenets. These tenets, being called false tenets by Lakoff and Johnson, are completely opposed and refuted by them (ibid). Some of the basic tenets of traditional theory are: Metaphor is a matter of words, not though; metaphorical language is not part of ordinary conventional language, and that Metaphorical language is deviant (Lakoff and Johnson, 1999 p: 119). In reaction to this traditional view on metaphor, the conceptual theory has been advanced by Lakoff and his colleagues (McGlone 2007 p: 110). Conceptual metaphor theorists "make it very clear that they do not view metaphor as being solely (or even primarily) linguistic phenomena; rather they consider it a mode of conceptual representation" (ibid, p: 112). Similarly Shnitzer and Pedreira (2005) say that there are mainly two approaches to the study of metaphor: 'Classical' and 'Cognitive'. They argue that the distinction between the two is "based on whether one is willing to countenance literal meaning (i.e., the classical/figurative distinction), or one rejects the notion of literal meaning in favor of the view that all language is metaphoric" (Schnitzer and Pedreira, 2005, p: 32). Cognitive approach, which is another name for "conceptual approach', can be considered the most influential metaphor theory. This approach, as it was mentioned above, is mainly and strongly supported by Lakoff, Johnson, and Turner, and states that "metaphors are not special, but are rather at the core of ordinary language and indeed at the core of human experience" (Schnitzer and Pedreira, 2005, p: 34). In this framework it is argued that the use of metaphors is necessary and unavoidable because there is a strong relation between metaphor, thought and language. Recent metaphor theories put the emphasis on the study of metaphors because it is believed that understanding the way metaphors are used and perceived provides useful knowledge about how brains, minds, and language are connected to each other.

Within the framework of the conceptual theory of metaphor, it is maintained that many abstract concepts are understood through establishing metaphoric connections between the abstract concepts and the concrete objects existing in the real world. Indeed for understanding any abstract and complex concept, there are some basic units such as up-down, center-periphery, and front- back which act as bases and these bases establish some grounding for metaphors to be understood (Schnitzer and Pedreira, 2005, p: 35). "Without any grounding at all, it would be impossible to determine what is being characterized in terms of something else" (ibid, $p: 35$ ). In sum, we argue that according to new trends in linguistics and psycholinguistics, the use of metaphor in ordinary uses of language is a commonplace activity and indeed metaphors appear in all text-types. However, the presence of metaphors in all text-types and in everyday uses of language does not imply that metaphors are ordinary linguistic elements without any special and additional shades of meaning. In fact, the selection and use of metaphoric elements within a text can be considered to be semantically motivated.We argue that metaphorical expressions are highly motivated elements and are essential to the meaning to be negotiated from the text and any elimination or paraphrasing of them by literal language distorts the meaning of the text. In the case of literature texts, the special meanings negotiated by metaphors produce literary effect of the text. Before analyzing our sample literary text, some points regarding the degree of novelty of metaphorical elements seem to be worthy of attention.

\section{Novelty of metaphor}

By novelty we mean the degree to which the use of metaphoric elements is creative or the degree to which the metaphor has metaphoric force. For determining the degree of novelty or metaphoric force we suggest three 
International Journal of Applied Linguistics \& English Literature

ISSN 2200-3592 (Print), ISSN 2200-3452 (Online)

Vol. 1 No. 7; November 2012 [Special Issue on Applied Linguistics]

criteria to be involved. The first criterion is whether the metaphor is conventional or new. We deliberately avoid the notion of dead metaphor because following Lakoff and Johnson (1999) we argue that there is a difference between conventional and dead metaphors. In the case of dead metaphor the conceptual mapping between the metaphor and the original conceptual metaphor has long ceased to exist (Lakoff and Johnson, 1999, p: 124). Lakoff and Johnson point out that a good example of a dead metaphor is the word pedigree which originally came from the French pe de gris meaning "foot of a grouse" and nowadays it refers to the family three diagram. They argue that "the image mapping from a grouse's foot to a family tree diagram has ceased to exist as a living part of our conceptual system" (ibid). By conventional metaphor it is meant those instances of metaphoric expressions (e.g. the leg of the table, it escapes me, I don't follow) which are not used for the first time. Conventional metaphors through frequent uses have lost their sense of novelty and as Halliday mentions they have become part of the system of language (see Halliday, 1985). Concerning conventional metaphors, it is argued that the conceptual metaphoric "mapping is still alive" (Lakoff and Johnson, 1999, p: 125). In contrast with conventional metaphors, new metaphors refer to those metaphors which the producer of the text uses for the first time. In other words, new metaphors are those instances of metaphoric expressions which are of high degree of novelty and, as suggested by people working within the framework of connectionism, they form links between different networks (Schnitzer and Pedreira, 2005, p: 45). Understanding of these novel metaphors involves establishment of the connection between different networks. Over times the novel metaphors lose their metaphoric force because the connections between networks become "so well established as to become integrated into the relevant network themselves, losing ... the sense of being metaphorical (ibid, p: 44). In this way most metaphoric expressions by being frequently used through ages have lost their metaphoric force and have become part of the system of language. Halliday (1985) mentions that "there are many instances where a metaphoric expression has become the norm, and this is in fact a natural process of linguistic change (p: 321 ).

The second criterion for determining the degree of novelty or metaphoric force of a metaphor is whether or not the metaphor is used strategically. This is of course a context- dependent factor and is determined through the way a metaphor is used in a specific text by the producer of the text. By strategic use of metaphors we mean those instances of metaphoric wordings which are consciously and deliberately used for the purpose of adding indirect, inferential and additional meanings to semantic realm of the text. By non- strategic use of metaphors, we mean those uses of metaphors where no intention of indirectness or metaphoric use of language is involved. When a conventional metaphor is used strategically, we suggest that it gains novelty or metaphoric force in that specific context. As we will see in section 4, there are cases of conventional metaphors whose sense of novelty or metaphoric force is created by being used strategically in a specific context of use.

The third factor relating to novelty and metaphoric force of a metaphor is to consider whether it is marked or unmarked. By markedness we mean the relation of a metaphor to its literal or congruent realization (Halliday, 1985). When the use of a metaphor can be considered as normal and frequent as its literal realization, we can consider the metaphor as an unmarked one. But when the literal realization of a metaphor is the norm, while the metaphoric use is not the norm, we consider the metaphor as the marked one. In sum, for determining the novelty and metaphoric force of a metaphor, we should take into account three criteria: whether a metaphor is a conventional or new, whether or not it is used strategically, and whether the metaphor is marked or unmarked. The following section of the paper is devoted to the analysis of one literary text in terms of the presence of metaphoric expressions, their coherent connection to each other, and their relatedness to the topic of the texts.

\section{The analysis of a poem in terms of its conceptual and linguistic metaphors}

The text to be analyzed here is a poem written by Andrew Marvell:

\section{TO HIS COY MISTRESS}

HAD we but world enough, and time,

This coyness, Lady, were no crime

We would sit down and think which way

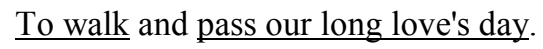

Thou by the Indian Ganges' side

Shouldst rubies find: I by the tide

Of Humber would complain. I would 
Love you ten years before the Flood,

And you should, if you please, refuse

Till the conversion of the Jews.

My vegetable loveshould grow

Vaster than empires, and more slow;

An hundred years should go to praise

Thine eyes and on thy forehead gaze;

Two hundred to adore each breast,

But thirty thousand to the rest;

An age at least to every part,

And the last age should show your heart.

For, Lady, you deserve this state,

Nor would I love at lower rate.

But at my back I always hear

Time's wingèd chariot hurrying near:

And yonder all before us lie

Deserts of vast eternity.

Thy beauty shall no more be found,

Nor, in thy marble vault, shall sound

My echoing song: then worms shall try

That long preserved virginity,

And your quaint honour turn to dust,

And into ashes all my lust:

The grave 's a fine and private place,

But none, I think, do there embrace.

into ashes all my lust:

Now therefore, while the youthful hue

Sits on thy skin like morning dew,

And while thy willing soul transpires

At every pore with instant fires,

Now let us sport us while we may,

And now, like amorous birds of prey,

Rather at once our time devour

Than languish in his slow-chapt power.

Let us roll all our strength and all

Our sweetness up into one ball,

And tear our pleasures with rough strife

Thorough the iron gates of life:

Thus, though we cannot make our sun

Stand still, yet we will make him run. 


\section{International Journal of Applied Linguistics \& English Literature}

ISSN 2200-3592 (Print), ISSN 2200-3452 (Online)

Vol. 1 No. 7; November 2012 [Special Issue on Applied Linguistics]

In the above poem, we have underlined the metaphoric expressions. We have also illustrated the metaphors in the table \# 1 appearing in the Appendix. Considering its content and theme, the poem can be divided into three sections. Lines 1 to 20 express the first part of the poem. The second part of the poem is expressed in lines 21 to 33 . And the last part of the poem is expressed in lines 34 to 48 . The topic or theme of the first part of the poem is that Love is deeply related to time and place: (the topic of the first part is stated in the first line: Had we but world enough and time). In the first part of the poem, the speaker's love and also the seemingly innocent character of the beloved one are described. The concepts used in this section to describe the speaker's love are TIME and PLACE: Had we but world enough, and time, This coyness, Lady, were no crime. Through these lines, the concepts of place, time, and the innocence of the beloved one are established. The first linguistic metaphor we encounter in the poem is: which way to walk which is a conventional metaphor and is expressed in lines 3-4. This conventional metaphor is a linguistic manifestation of a conceptual metaphor of "The Love Is A Journey" (Lakeoff and Johnson, 1999, p: 123). This metaphor is strategically used to reinforce the theme of the section and is coherently linked to the next metaphor. We suggest that this conventional metaphor gains its novelty and metaphoric force by virtue of the coherent connections with the previous metaphor and also with the topic of the first section of the poem in this specific context. The second metaphor used in the poem is: and pass our long love's day. The metaphor seems to be a new one because it is a reflection of a new conceptual metaphor. In this metaphor the concept of Love Is Time is manifested. The degree of novelty or metaphoric force of this linguistic metaphor is high. Both of the metaphors are related to each other and to the topic of the section. In line 11 the most important metaphor is realized: $M y$ vegetable love should grow vaster than empire and more slow. Here again we encounter with a new metaphor; Love is materialized through a new conceptual metaphor: Love Is Vegetable. Vegetable is deeply related and dependant on a place. And vegetable also needs time to grow. The phrases: vaster than empire and more slow again reinforce the relatedness of love to place and time. Here again we can notice the coherent relatedness of this metaphor to the previous ones on the one hand and to the topic of the first section of the poem on the other hand. The last metaphor in this part is: Nor would I love with lower rate. Here again the conceptual metaphor developed in the poem (i.e. Love Is An Object Related To Time And Place) is manifested through the metaphoric word rate which is a concept related to amount and speed simultaneously. That is to say, the word rate is used ambiguously here. There are different metaphoric dimensions for this word. On the one hand, the word rate activates the concept of amount and size and on the other hand it activates the concept of speed. While the size conception of rate is coherently linked with the other metaphors used in this section, the speed dimension of the word seems to be in contrast with the rest of the metaphors used in this section. But as we will see later in this section, it is coherently connected to the metaphors used in the second part of poem which develops the sense of speed.

Underlying all linguistic metaphors used in the first part of the poem is a common conceptual metaphor that is Love Is Journey. That is to say, all linguistic metaphors used in the first section of the poem are the realizations and manifestations of the same conceptual metaphor which is in turn the direct reflection of the topic or theme of the poem. It is through this conceptual metaphor that the message of the poem is communicated. Since one common conceptual metaphor underlies all linguistic metaphors and since the topic of the poem is developed through this conceptual metaphor, we come upon such coherent links among the metaphors used in the text.

The second section of the poem is expressed through lines 21-22. The theme of this part seems to be in contradiction with the theme of the first part. The textual manifestation of such a contradiction is the word 'But' used at the beginning of the line 21 which is also the beginning of the second part of the poem. The first metaphor used in the second section of the poem is: Time's wingèd chariot hurrying near. In contrast with the metaphors used in the first part (with the exception of the last metaphor of the first section, i.e. the Rate metaphor) which imply duration and length of time, this metaphor seems to imply the shortness of time through the word hurrying. While in the first part of the poem, the reader infers a sense of stability, in the second section of the poem one feels the state of fluctuation and change and this sense of fluctuation is established and reinforced by the first metaphor in the section. The second metaphor of this part is: Deserts of vast eternity. While this metaphor seems to have little coherent connection with the first metaphor of the second part of the poem, it has some deep underlying connection with one of the metaphors used in the first section (Vaster than empires,). Both of the metaphors (i.e. Deserts of vast eternity and Vaster than empires) are the linguistic manifestations of the same conceptual metaphor: Love Is Big and Vast.

As it was mentioned above, there is a sense of contradiction and paradox between the first and the second parts of the poem. As it was mentioned above, the word 'But' initiates a sense of contrast between the first and the second parts of poem. The metaphor (Time's wingèd chariot hurrying near) also reflects a sense of contrast between speedy passage of time with the idea of the depth and duration of Time established in the first part of the poem. As 
International Journal of Applied Linguistics \& English Literature

ISSN 2200-3592 (Print), ISSN 2200-3452 (Online)

Vol. 1 No. 7; November 2012 [Special Issue on Applied Linguistics]

another instance of contrast between these two parts, we can mention that while the depth and stability of the beauty of the beloved one is highly emphasized in the first section of the poem, in the second part, the speaker says: Thy beauty shall no more be found. We suggest that the sense of paradox and contradiction is deliberately created in the poem to reflect the paradoxical nature of love itself.

The next metaphor we meet in the second part of the poem is: then worms shall try that long preserved virginity which reflects a kind of hostility to the beloved one which is in contrast with the exaggerated admiration of the characteristics of the beloved one established in the first part of the poem. In spite of the seemingly apparent contrast between the two parts which is reflected and foregrounded in this metaphoric expression, there are some underlying hidden thematic connections between the conceptual metaphors developed in the first and second sections of the poem. As it was mentioned above, the dominant metaphorical concept in the first section of the poem is Love Is A Journey. Journey has aspects of Time and Place. Implied from this conceptual metaphor is the fact that Love like a journey has aspects of Time and Place. An important metaphoric concept in the second part of the poem which is related to the dominant conceptual metaphor of the poem (i.e. Love Is A Journey) is: Time Passes Quickly. It is a well -established fact that if the Time of something is finished, one can do nothing about it. It is also a well known concept that everything should be done in its appropriate time limit. To materialize the ideas of the looseness of Time and the necessity of doing something in its appropriate time limit, different linguistic metaphors are used in the second part of the poem. The linguistic metaphors of: then worms shall try that long preserved virginity, and your quaint honour turn to dust, and into ashes all my lust: are all the manifestation of the concept of looseness of time and the uselessness of doing something outside its time limit.

The third part, which is the last part of the poem, begins with a conventional metaphor: while youthful hue sits on thy skin. This metaphor is introduced by the adverbs 'Now' and' Therefore', which establish a textual and thematic connection between the third part and the second part of the poem. The metaphor is again the linguistic manifestation of the conceptual metaphor (Time Passes Quickly). The implied meaning of this conceptual metaphor, as it was mentioned above, is that there is a time limit for everything. In this point the speaker of the poem suggests that youth is not a permanent characteristic and the beloved one should use this opportunity. Both the conceptual metaphor and its linguistic manifestations are well established metaphors. What creates the novelty or metaphoric force of the linguistic metaphors in this specific context is the coherent interrelatedness of the metaphors within the poem. We speculate that it is through the strategic use of metaphors that the novelty and metaphoric force and hence the literary effect of the text are created in the literary text-type. The second metaphoric expression realized in the third section of the poem is: thy willing soul transpires at every pore with instant fires. This linguistic metaphor has a coherent connection with the previous one. This connection is established between these two metaphoric expressions because the words skin and pore belong to the same semantic field. The collocation of the word transpires and the phrase instant fires is a new one giving a sense of novelty to the metaphoric expression. The words transpire and pore are more associated with water than fire. And this new association gives novelty to the metaphor, creating the literary effect in the minds of the readers of the poem. The image of the Fire activated here reinforces the image of Ashes being produced in the previous section of the poem. The metaphor appeared in line 39 (time devour) is a linguistic metaphor reflecting the concept that for everything There is a Time Limit which is already activated in previous lines of the poem. This coherent link again establishes the interconnection between the lines of the poem and this enhances the degree of coherence of the literary text. The other metaphoric expression used in this part (Let us roll all our strength and all our sweetness up into one ball,) is a new linguistic metaphor. The underlying meaning of the metaphor is that we should use our opportunities and the time we have been offered in the best way. This metaphor reinforces the themes and the concepts already established in the previous lines of the poem. The last metaphor which we want to discuss is: And tear our pleasures with rough strife thorough the iron gates of life. This linguistically new metaphor reflects and materializes the same concept which is manifested in the previous metaphor, indirectly suggesting that we have inadequate time and we should use the opportunities offered to us in the best possible way.

\section{Summary and conclusion}

By analyzing a literature text in terms of its linguistic and conceptual metaphors, we found out that metaphors in literature texts are core elements of the texts through which the topic or theme of the text unfolds. Being core elements, we speculated that metaphors especially novel metaphors with a high degree of metaphoric force within a text are coherently linked to each other on the one hand and to the topic of the text on the other. Indeed, using a poem as our data, we found a high degree of coherence among the novel metaphors used in our analyzed text. The linguistic metaphors used within the text contribute to the enhancement of the unity of the whole text through their relatedness to the topic of the text. They also contribute to the literary effect of the text through being thematically 
International Journal of Applied Linguistics \& English Literature

ISSN 2200-3592 (Print), ISSN 2200-3452 (Online)

Vol. 1 No. 7; November 2012 [Special Issue on Applied Linguistics]

motivated elements. Therefore the idea that metaphors are an ornamental aspect imposed upon ordinary language cannot be acceptable. Metaphors are indeed core elements in all text-types in general and in the literary texts in particular. On the basis of the analysis of our data, we suggest that appearance of metaphors in the actual uses of language is not a matter of text. Rather metaphors are directly the result of the discourse elaboration process.

In general we maintain that metaphoric elements are realized in the texts to fulfill different discoursal functions. As far as literary texts are concerned, we suggest that metaphoric expressions by being thematically motivated elements add to the improvement of the unity of the whole text. In literary text, metaphors can be regarded as a special discoursal strategy fulfilling the discoursal functions of indeterminacy and dehabitualization (Lotfipour, 1992, p: 199). On the basis of our study as well as on the basis of the findings of previous studies on metaphor, we suggest that:

1- Linguistic metaphors are manifestations of the underlying conceptual metaphors.

2- Metaphors are special discoursal strategies as well as special textual strategies.

3- Metaphors are a matter of discourse rather than text.

4- Metaphors contribute to fulfill different functions in different text-types. As far as literature texts are concerned, metaphors, in addition to fulfilling other functions, contribute to the establishment of unity of the text.

5- Metaphors in literature have a high degree of metaphoric force. The metaphoric force or novelty of metaphoric expressions is the result of using new metaphors as well as the strategic use of already established conventional metaphors.

6- The use of new metaphors such as "vegetable love" in the literary text contributes to the establishment of different discoursal functions such as indeterminacy and dehabitualization (Lotfipour, 1992 p:199).

7- It is through literature that new conceptual metaphors are created and added to our conceptual system.

\section{References}

Candlin, C. and Lotfipour- Saedi, k. (1983). Processes of discourse. Journal of Applied Language Studies 1(2), 103-310.

Gibbs, R. and Cameron, L. (2008). The social- cognitive dynamics of metaphor performance. Cognitive Systems Research 9, p: 64- 75.

Fairclough, N. (2010). Critical Discourse Analysis, Longman UK.

Halliday, M.A.K. (1985). An introduction to Functional Grammar, London: Edward Arnold.

Halliday, M.A.K \& Hasan` R. (1976). Cohesion in English. London: Longman.

Halliday, M.A.K. Hasan` R. (1990) Language, Context and Text: Aspects of Language in a Social Semiotic

Perspective Oxford university Press. Oxford

Lakoff, G., \& Johnson, M. (1999) Philosophy in the Flesh. Basic Books,Newyork.

Lotfipour- Saedi, K. (1989). Analyzing Literary discourse: Implication for literary translation. A paper presented at the first Tabriz University Conference on translation. Iran Tabriz University.

Lotfipour- Saedi, K. (1992). Analysing Literary Discourse: Implications for Literary Translation'Meta 37/2 P: 193-203.

McGlone, M. S. (2007) 'What is explanatory value of a conceptual metaphor'Language and Communication. 27 p. $109-126$

Schnitzer, M.L.,\& Pedreira, M.A. (2005). A neuropsychological theory of metaphor' Language Science. 27 p. 31-49.

Tendahl, R.W., \& Gibbs, J. (2008) 'Complementary perspective on metaphor: Cognitive linguistics and relevance theory’ Journal Pragmatics. 40, p.1823-1864. 
International Journal of Applied Linguistics \& English Literature

ISSN 2200-3592 (Print), ISSN 2200-3452 (Online)

Vol. 1 No. 7; November 2012 [Special Issue on Applied Linguistics]

\section{Appendix}

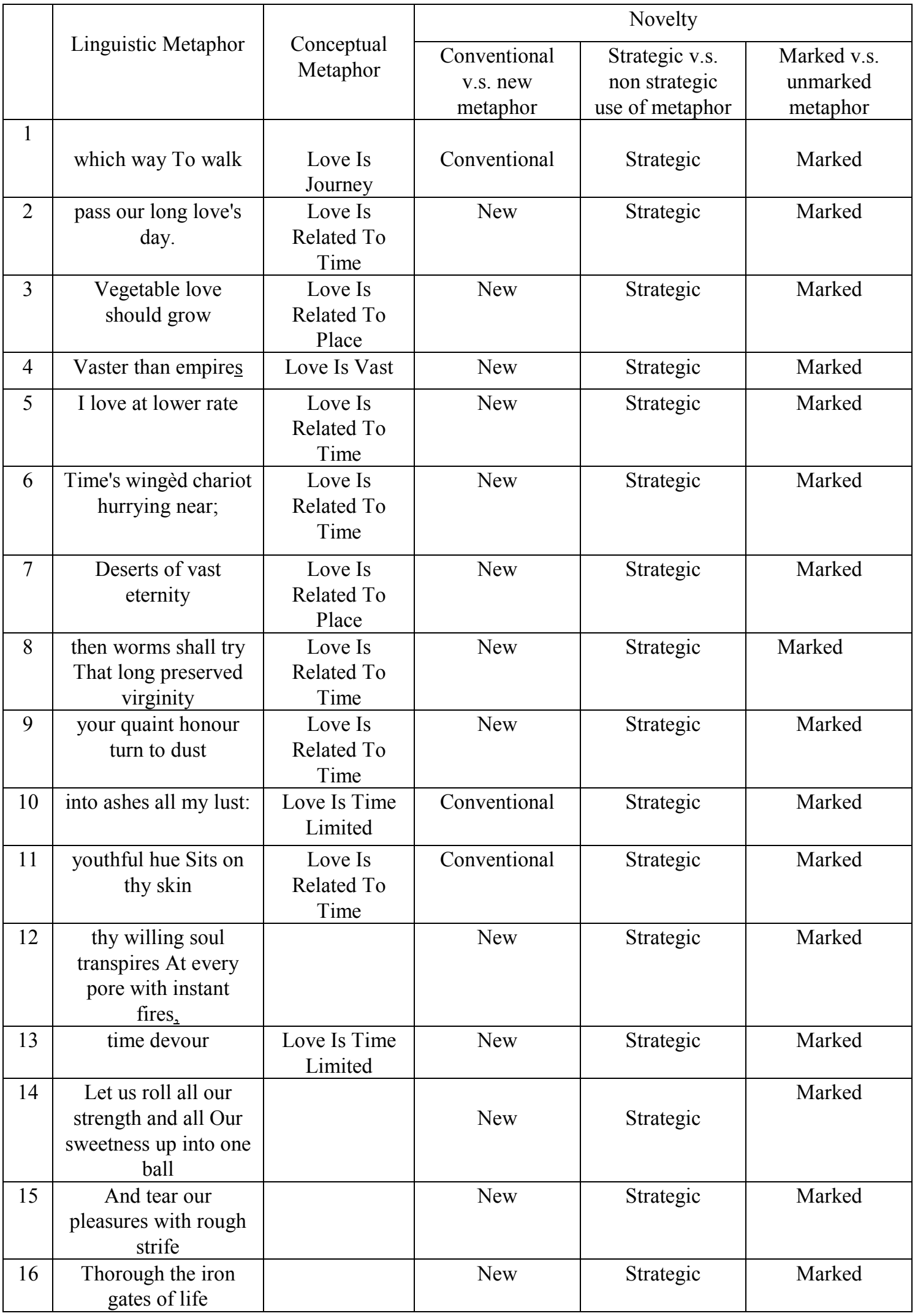

